\title{
Intonational Marking of Given/New Information in Oral Storytelling An Analysis of Intonation of Information Structure in Narrative Discourse
}

\author{
Yasmin M. Al-Sayed \\ Intonational Marking of Given/New Information in Oral Storytelling: An Analysis of \\ Information Structure of Narrative Discourse
}

\begin{abstract}
Intonation is one of the prosodic features that influence the conveyed meaning of discourse. It refers to the variations in the pitch of a speaker's voice used to convey or alter meaning. Information structure of spoken discourse is closely related to intonation as intonation serves to convey the organization of information in an utterance.

The present study is an attempt to investigate the intonational marking of given/new information in oral storytelling through conducting an instrumental analysis of intonational contours. Two approaches are adopted as the theoretical framework: Pierrehumbert's Autosegmental Metrical Approach (1980) and Prince's Assumed Familiarity Approach.

Key words: intonation, information structure, narrative storytelling, Praat, Autosegemental Metrical Approach, Prince's taxonomy of given/new information
\end{abstract}

\section{1- Introduction:}

The present paper proposes an approach for the analysis and investigation of the role played by intonation in discourse. More specifically, it aims to clarify the relation that holds between discourse intonation and information status/structure in spoken discourse. Given/New information is the aspect of information structure under investigation. Oral narrative is the type of spoken discourse to be discussed and analyzed.

Along with stress and rhythm, intonation is one of the prosodic features that performs diverse functions and affects discourse and its meaning. Intonation is an interesting, yet complex, area of research. Though this area of language has been neglected or regarded peripheral, there is an increased interest in examining the intonational aspect of speech. This is due to multiple of reasons. First, the tremendous technical advance provides wide access to "inexpensive speech analysis and synthesis software ... large databases facilities" (Vaissiere, 2004, p.1). Second, the conceptual advance in the formal representation of pitch contours has encouraged intonational investigation. Finally, the interest in 
the communication process has drawn attention to the role played by intonation in interaction (Ibid.). However, it is still difficult to study intonation because there is no yet broad consensus over significant related issues, for example, the definition and pereception of the concept, the object and aim of intonation studies, and the representation of intonation.

Storytelling is the form of spoken discourse under analysis. It is a form of narrative discourse that recounts a story which "contains a sequence of events that take place over a time period." (Akinsanaya \& Bach, 2014, p.1).

The structure of the present study follows the following pattern: the adopted theoretical framework, the analysis of the selected data, findings, and conclusion.

\section{2- Objectives of the study:}

The present study attempts to conduct the following:

1) Investigation of the concept of intonation, its constitutive elements, and its significance in the study of spoken discourse.

2) Identification of given/new information which forms a constitutive part of the information structure of discourse in general and spoken discourse in particular.

3) Implementation of instrumental analysis of intonational contours that represent given/new information in discourse.

4) Investigation of the intonational marking of given/new information of discourse through the investigation of its assigned pitch accents.

\section{3- Methodology:}

Two approaches are adopted as the theoretical framework for implementing the research objectives: Pierrehumbert's Autosegmental Metrical Approach (1980) to intonation and Prince's Assumed Familiarity approach as a taxonomy of given/new information (1981). The analysis is conducted as follows:

1) Identification and classification of referents (nouns ,noun phrases, or pronouns) that carry information in the selected data into Brand New, Inferred, or Evoked according to Prince's taxonomy.

2) Annotation of the data using Praat software that helps show the pitch and intensity of the information referents previously identified. The annotation is applied manually to the selected referents.

3) Assignment of the appropriate pitch accent, whether $\mathrm{H}^{*}, \mathrm{~L}^{*}, \mathrm{H}^{*}+\mathrm{L}$, $\mathrm{H}+\mathrm{L}^{*}, \mathrm{~L}^{*}+\mathrm{H}$, or $\mathrm{L}+\mathrm{H}^{*}$, to each referent according to Pierrehumbert's classification. 


\section{Yasmin M. Al-Sayed}

\section{4- Data \& Data Source:}

The chosen data for analysis is an American short story entitled "A Pair of Silk Stockings". It is written by the American author Kate Chopin (1851-1904). The story was first published in 1897. For the specific nature and purposes of the present research, an oral narration of the story was used. It is read by an American female storyteller. The audio of the story was downloaded from The Voice of America (VOA) American Stories website (WWW.manythings.org/voa/stories/). The duration of the audio is 13 minutes and 49 seconds.

\section{5- Background:}

\section{5-1- Intonation:}

Verbal communication is a process for transmitting and conveying information. It involves a sender, a receiver, a code, and a medium. The sender's thoughts, feelings, emotions, and attitudes are encoded into a recognizable form. Then, the encoded message travels through a particular channel to the receiver who, in turn, decodes the message. A code is "any system of signals used for sending messages" (Crystal, 1995, p.60). In verbal communication, the participants employ verbal (oral/spoken) language as the code for transmission. The final product is discourse.

Discourse is "a continuous stretch of speech, a product of using language for communication" (Karpus, 2012, p. 96). The term was first introduced by James Kinneavy whose idea of discourse is based on "the communicative triangle the three points of which are the speaker (or writer), the audience, the outer world and the triangle itself which represents the text or the message. (Ibid., p.97).

An integral part of spoken discourse is INTONATION. Discourse participants employ intonation to convey information in speech. Central to intonation is the modulation of pitch over the utterance. In other words, it is "the use of pitch variations in the voice to communicate phrasing and discourse meaning in varied linguistic environments" (Levis \& Wichman, 2015, p.139). Crystal regards intonation as a set of prosodic features such as variations in pitch, loudness, duration, and silence. Cauldwell (2002) maintains that both the speakers' choice and their reactions towards the persistent task of making sense to their hearers in context in real time determine the communicative function of intonation.

Roach (1992) maintains that intonation has TWO diverse senses: a restricted sense and a broader and more popular sense. The former sense refers to "the variations in the pitch of a speaker's voice used to convey or alter meaning" (p. 56). In other words, it is 
a means for conveying information in speech which is independent of the words and their sounds. Central to intonation is the modulation of pitch, and intonation is often thought of as the use of pitch over the domain of the utterance. (Nolan, 2006, p. 433)

In the latter sense, intonation is equivalent to prosody where "variations in such things as voice, quality, tempo, and loudness are included" (Roach, 1992, p. 56).

\section{5-1-1- Approaches to Intonation:}

Three basic strands (methodologies) of research on intonation in discourse are identified: intonation-as-grammar, intonation-asinformation flow, and intonation-as-contextualization. In the first approach, an attempt is made to correspond final falling or rising with sentence type; i.e. declarative, interrogative, or exclamatory sentence types (Couper-Kuhlen \& Selting, 1996). In this approach, intonation assists in recognizing the grammar and syntactic structure of the utterance.

The second approach, intonation-as-information flow, relates intonation to information flow: "the movement of ideas into and out of active, semi-active, and inactive state of consciousness" (Couper-Kuhlen, 2001, p. 15). One instance of such approach is Chafe's work (1976, 1980, 1994). Two units of intonation are established: the intonation unit and the accent unit. The former "encompasses the information that is the speaker's focus of consciousness at a given moment", whereas the latter is "the domain of activation for new, accessible, and/or given information" (Chafe, 1994, p.39). The main distinctive features of the current approach is that it pays more attention to unit segmentation and inter-unit continuity, and it is developed out of close observation of "real discourse rather than from introspection and constructed examples" (CouperKuhlen, 2001, p. 15).

Intonation-as-contextualization approach involves the understanding and interpretation of linguistic signs and embedding such signs in a relevant context. This approach is regarded as a more deliberately interactional approach, i.e. it pays more attention to participants' interaction.

\section{5-1-2- Description of Intonation System:}

'Pitch', which can be high or low, is the basic intonational feature. The overall behavior of pitch is called 'tone'. It can be level (static) or moving (rising or falling). The unit of intonational analysis is called the tone 


\section{Yasmin M. Al-Sayed}

unit'. Specific concepts are central to comprehending the intonational pattern; namely, prominence, intonational contour, phrasing, and pitch range. Each will be discussed briefly.

1) Prominence: it refers to stress displayed over syllables in an utterance. "The perception of prominence is triggered primarily (in English) by a pitch excursion, upwards or occasionally downwards" (Levis \& Wichmann, 2015, p.144). Other phonetic features, together with pitch, help to mark prominent syllables. These include syllable lengthening and full articulation of individual segments: "... particular syllables of words can be picked out from the stream of speech by some combination of increased loudness and/or duration, greater force and/or precision of articulation, and pitch movement and/or widened pitch range" (Ladd, 2001, p.1381).

2) Contour: it refers to "the movement of pitch, which correlates with the fundamental frequency (f0)" (Heusinger, 1999, p.14).

3) Phrasing: it means the division of speech into chunks by means of intonation. The sequence of words is divided "into intonational units, the intonational ... phrase" (Levis \& Wichmann, 2015, p.144).

There are TWO approaches to the study and investigation of intonation. The former is the British model, which will be discussed below. The other is the Autosegmental Metrical approach which will be discussed in details in the Theoretical Framework section of the present paper.

\section{5-1-2-1- The British Approach to Intonation:}

According to Roach (1992), "the approach most widely used in Britain takes the tone unit as its basic unit and looks at the different pitch possibilities of the various components of the tone unit" (p.56). Tone unit, also known as tone groups or intonation phrases, are parts of connected speech ending in a tonic (sentence stress and intonation, p.139). To Brazil (1994), a tone unit is "the basic building block of speech", which consists of "either one or two prominent syllables" (pp. 8, 9). Thus, the tone unit starts after a tonic syllable and ends in a tonic.

The tonic, also known as the nucleus, is the last stressed syllable of sentence which has the strongest stress. It displays pitch change, or a change in the voice height. This associated change is known as 'tone'. The change of the speaker's voice-height is not confined to the tonic syllable, but it continues to the tail, where no further change of pitch occurs. 
Besides the tonic, the tone unit is composed of the following parts:

1) Tail: it is the unstressed syllable following the tonic.

2) Pre-head: the unstressed syllable before the first stress in the tone unit. It starts with a relatively low pitch. Gradually, the pitch goes higher on the first stressed syllable of the head.

3) Head: it starts with the first stressed syllable and ends with the last unstressed syllable before the tonic. Throughout the head the pitch gradually falls down. This is called 'downdrift'.

The following is an example utterance where the tone unit and its parts are shown:

She 'wanted to 'face the 'problems on 'TUES day

Prethead head tall

In the above example, the tonic syllable is 'TUES', indicated by capitalization and bold faced. The boundary of the tone unit is marked by two vertical lines. The stressed syllables are indicated by (') that is placed directly before the stressed syllable.

The following example is an utterance that further demonstrates how pitch changes over the partsconstituting the tone unit:

'Have you 'seen this MOvie?

In the previous utterance, there is no pre-head. Rather, the utterance starts directly with the first stressed syllable of the head $(\boldsymbol{H a})$. The pitch starts directly relatively high and falls gradually throughout the head. The tonic syllable (MO) is directly preceded by a rising arrow to show a rising pitch. The rest of the word (vie) is the tail and it is unstressed.

The above system is similar to other approaches of intonation analysis. For instance, in Brazil's model, which is based on the work of Halliday (1973), the tone unit consists of FOUR options: prominence, tone, key, and termination. They will be briefly discussed:

1) Prominence: it means "changes in stress, pitch or emphasis that allows for added meaning to be inferred in what is being spoken" (Hadley, 1996, p.2).

2) Tone: it is divided into Falling, Rising, Fall-Rise, Rise-Fall, and Level.

3) Key: it consists of three levels: High, Mid, and Low, each conveying distinct meaning.

4) Termination: it refers to "the choices a speaker makes in tone, key, and prominence" (Ibid., p.3). 


\section{Yasmin M. Al-Sayed}

\section{5-2- Functions of Intonation:}

Intonation is an aspect of language that performs diverse functions. First, intonation performs lexical and morphological marking. In other words, intonation highlights and stresses the tonic syllable within the tone unit. This is achieved through strongly articulating the syllable. Accentuation of tonic syllable can convey different meanings including the following:

1) Contrast: in the sentence, "I 'don't want to 'know where he's 'travelling FROM. I $\square$ want to $\square$ know where he's $\square$ travelling $\underline{\text { TO"}}$ ", the accentuation of the two tonic syllables 'from' and 'to' clarifies the contrast in the presented information.

2) Emphasis: accentuation helps to emphasize the most important piece of information in the utterance. Roach (1983) maintains that

... the tonic syllable will tend to occur on the last

lexical word in the tone-unit, but may be placed earlier in the tone-unit if there is a word there with greater importance to what is being said. (p.144)

Second, intonation performs a syntactic function. Intonation serves as a means of disambiguating ambiguous sentences. For example, the way the following two identical sentences are phrased affects the conveyed meaning:

1) |'Those who 'sold $\backslash$ quickly $\mid$ 'made a ,profit $\mid$. This sentence means 'a profit was made by those who sold quickly.

2) |'Those who sold $\mid$, quickly, made a ,profit $\mid$. This means 'a profit was quickly made by those who sold'.

Another element of intonation that serves a grammatical function is the choice of tone on the tonic syllable to indicate a specific grammatical structure. For example, yes/no question is indicated in speech by a rising tone, whereas employing the falling tone indicates questions that start with interrogative words.

The third function performed by intonation is related to its role in discourse, where it "looks at the larger context in which sentences occur" (Roach, 1983, p.147). This role is regarded as a comparatively new area of research. The term 'discourse' refers to "the full text of an oral or written situation" (Karpus, 2012, p.97). It is the "product of using language for communication" (Ibid., p.96). Discourse is not just a sequence of scattered unrelated sentences/utterances. Rather, there must be a relation to link 
them into a larger coherent whole. In written discourse, a variety of grammatical and typographical features exist as to how to link the presented information. Examples include the usage of "conjunctions, sentence adverbials, ... discourse markers, ... paragraphs, headings, punctuation, capitalization, and font changes" (Levis \& Wichmann, 2015, p.151).

However, in spoken discourse, where visual aids are absent, participants employ different features to signal text and information structure, one of which is intonation. The communicative value of the utterance is affected by intonational variations on the basis of a small set of choices which relates to "a set of meaningful oppositions that together constitute a distinctive subcomponent of the meaning-potential of English" (Karpus, 2012, p.97).

Intonation serves TWO main functions in discourse: "... to focus the listener's attention on aspects of the message that are most important, and ... the regulation of conversational behavior" (Roach, 1983, p.147). Focusing attention, the first area, can be achieved through the exploitation of the intonational features. Pitch accent can be placed on "the appropriate syllable of one particular word in the tone-unit" to mark the most important word or "the word with important information content" (Ibid., p.148).

Also, through using the appropriate tone, it can indicate "whether the tone unit ... presents new information or to refer to information which is felt to be already possessed by speaker and hearer" (Ibid.). This implies the distinction between introduced types of information in spoken discourse. The classification includes 'Given' and 'New' information. The more predictable a word's occurrence is in a given context, the lower its information content, and "the tonic stress will tend to be placed on words with high information content" (Ibid.).

In summary, intonation in discourse is related to the rules "which govern the pitch movement beyond and between borders of tone units..." (Karpus, 2012, p.97). It has a communicative value as intonation is regarded as an aspect of interaction that conveys "information about the structure of the interaction, the relationship between the individual utterances, the interactional 'givenness' and 'newness' of information" (Brazil, 1980, p.3).

\section{5-2- Information Structure:}

Information structure (IS) refers to the organization of information within an utterance. It displays "how the information conveyed by a sentence is related to the knowledge of the interlocutors and the structure of their discourse" (Prevost, 1995, p. 62). It is "how the semantic content 


\section{Yasmin M. Al-Sayed}

of an utterance is packaged, and amounts to instructions for updating the information models of the discourse participants" (Ibid.). In distinguishing it from discourse semantics, information structure is "a Sentence Internal partition of the information in an utterance according to its relation to the discourse context under dichotomies such as ... given/new" (Steedman \& Kruijff-Korbayova, 2001, p.1).

Intonation and information structure are closely related; intonation serves to convey the information structure. Put simply, intonational features do not act in isolation. Instead, they form an operating system. For instance, the contour represents the speech act of the utterance; the phrasing indicates informational units; and prominence marks the focus of the utterance.

Several functions of intonational features are related to information structure, which motivates the division of the sentence into units, organizes the internal structure of these units, and accounts for the relation of the units to each other and to other parts of the discourse. (Heusinger, 1999, p.1).

Similarly, information structure serves how intonation is used. For instance, "the way a particular intonation contour is used is explained with reference to the function or the meaning of a sentence" (Ibid., p.3).

Information structure of the sentence is different from its syntactic structure. The syntactic structure consists of two basic elements that have a fixed function: the grammatical subject (in the nominative case) and the grammatical predicate (the verb or the verb phrase). Information structure, on the other hand, consists of psychological/underlying subject and psychological/underlying predicate. The psychological predicate is more important than the psychological subject because it is "the center of information of a sentence and its ultimate goal. This center of information corresponds to a constituent question" (Ibid., p.27). For example, the sentence "Karl goes to Berlin tomorrow" has different centers of focus and interest. This can be illuminated using the appropriate constituent question as shown:

"Who goes to Berlin tommorrow?" $\longrightarrow$ "KARL goes to Berlin tomorrow"

"Where does Karl go tomorrow?" $\longrightarrow$ "Karl goes to BERLIN tomorrow."

Thus, the psychological/underlying predicate stands for any constituent of the sentence that is focused on and new. The non focused part of the sentence is the psychological/underlying subject, which is already known. 
Intonation of the same sentence differs according to the focused part of the information. That is why intonation can help interlocutors distinguish the already-known part of information from the new information in the sentence.

\section{5-3- Narrative Discourse:}

Narrative is the telling of past events and it is present in a variety of genres including fables, tales, short stories and so forth. It gives an account not only of the events or the landscape of action, but also of what those involved in the action (and those telling it) know, think, or feel - the "landscape of consciousness" (Bruner, 1986, p.99). "A general principle $\ldots$ is that the speaker assumes that the hearer does not know the events denoted by the discourse occur" (Van Dijk, 1976, p.554).

Language, whether oral or written, is among the vehicles of delivering narrative. Gubrium \& Holstein (2007) contend that the study of narrative discourse has exhibited a recent change in focus from the complete texts towards a study of narrative practices. "Emphasis is on narrative activity as sense-making process rather than a finished product in which loose ends knit together into a single story-line" (Ochs \& Capps, 2001, p.15).

Oral storytelling style has been studied following quite different approaches. One approach is the investigation of oral storytelling in prosodic terms. The medium of conveyance is not only language, but also the human voice. Thus, oral storytelling employs intonation; the pitch range may rise or lower and the pitch accent may change. Human storytellers make sure to convey emotions and engage the listener.

\section{6- Theoretical Framework:}

The study adopts Prince's 'Assumed Familiarity' approach which is a taxonomy of given/new information (1981) and Pierrehumbet's 'Autosegmental Metrical' approach to intonation (1980). Each will be discussed in the following sections.

\section{6-1- Prince's Assumed Familiarity Approach:}

Given/New information is a means of regulating the flow of interaction and, subsequently, ensuring an efficient communication between the interlocutors. The speaker attempts to convey and relate two types of information: the information that he/she thinks the listener is familiar with and information that he/she is sure that the listener has not yet known. Thus, "the speaker tries, to the best of his ability, to make the structure of his utterances congruent with his knowledge of the listener's mental world" (Clark \& Haviland, 1977, p.4). The listener, on the other hand, comprehends in the same light. 


\section{Yasmin M. Al-Sayed}

Comprehension of Given/New distinction follows three subsequent steps:

1) "The listener insulates the given and the new information in the current sentence."

2) "He searches memory for a direct antecedent; a structure containing propositions that match the given information precisely."

3) $\mathrm{He}$ "integrates the new information into the memory structure, by attaching it to the antecedent found in step 2" (Ibid., p.5)

The identification of Given/New information in discourse has been an issue of thorough examination by linguists. For Halliday (1967), given information is related to the speaker's assumption that the hearer can predict or recover information from the context or the preceding text. New is "information ... that the speaker presents ... as not being recoverable from the preceding discourse" (p.204). For Chafe (1976), givenness is related to the speaker's knowledge of the information in the hearer's consciousness at the time of the utterance. Clark \& Haviland (1977) present a broader notion of 'shared knowledge'. According to this view, given is "information [the speaker] believes the listener already knows or accepts as true" and new is "information [the speaker] believes that the listener does not yet know" (p.4).

For Prince (1981), information is classified in two ways: as either discourse-old (i.e. "that which has been evoked in the prior discourse" (Ward \& Birner, 2001, p.123)) or discourse-new and hearer-old (i.e. the information that "the speaker believes to be present within the hearer's knowledge store" (Ibid.)) or hearer-new. Based on this view, Prince proposes an approach, named 'Assumed Familiarity', that postulates whether an entity is sensitive to discourse familiarity or hearer familiarity.

A discourse entity is a discourse model object akin to Karttunen's (1971) discourse referent; it may represent an individual (existent in the real world or not), a class of individuals, an exemplar, a substance, a concept, and so forth (Prince, 1981, p.235). Noun phrases represent the referents, and they are classified into THREE classes: New, Evoked, and Inferrable. Following is a discussion of each class.

The first category, New entities, refers to referents that have not been previously mentioned in the discourse model. This category is divided into TWO subtypes: Brand New (BN) and Unused (U). 'Brand New' 
refers to an entity that the hearer may need to create as it is neither previously mentioned in the discourse nor directly and instantly available to the hearer/reader given the current situation. It is both discourse-new and hearer-new. Consider the following example:

1) I got on $\boldsymbol{a}$ b us yesterday. (Brand New (BN))

The NP 'a bus' needs to be created in the hearer's consciousness.

Brand New is further divided into TWO subtypes: Anchored and Unanchored. Anchored entity is one that is represented by a noun phrase which is linked to some other discourse entity, by means of another noun phrase (Prince, 1981, p.236). The following example will provide illustration:

2) A guy I work with says he knows your sister.

The entity 'a guy' is Brand New (BN) that is understood through linking it to the referent 'I'. Unanchored entity, on the other hand, can stand by itself without being linked to some other entity.

Unused entity refers to a referent that "the hearer may be assumed to have a corresponding entity in his/her own model and simply has to place it in (or copy it into) the discourse model" (Ibid.). In other words, they are newly introduced in the discourse (discourse-new), but assumed to be already in the consciousness of the hearer (hearer-new). Consider the following example:

3) Noam Chomsky went to Penn. (Unused (U))

The second main category in Prince's taxonomy is Evoked (E) entity. They are considered given in that "an NP is uttered whose entity is already in the discourse-model" (Ibid.). Evoked entity is both discourse-old (i.e. previously mentioned in the discourse model) and hearer-old (i.e. active in the hearer's consciousness). Evoked entity is further classified into one of the following subcategories: Textually Evoked $(E t)$ and Situationally Evoked (Es). The former refers to entities previously mentioned in the discourse, and requires an explicit antecedent. They can be expressed by third-person pronouns and the definite article, as shown in the following example:

4) A guy I work with says he knows your sister.

The pronoun 'he' refers back to an entity that is discourse-old (previously referred to as ' a guy'). 


\section{Yasmin M. Al-Sayed}

Situationally Evoked (Es) entity is evoked by extra-textual situation, that is, "the hearer knew to evoke it all by himself, for situational reasons" (Ibid.). "Examples ... are referents expressed by first or second person pronouns [discourse participants] ... where the identifiability of the referent is tied to the extra-linguistic context of the utterance" (Howard, 2002, p.45), as shown in the following example:

5) Pardon, would you have change of a quarter?

The third category in Prince's taxonomy is Inferables (I), which is regarded as the most complex of the three. "A discourse entity is inferable if the speaker assumes the hearer can infer it via logical ... reasoning from discourse entities already Evoked or from other Inferables" (Ibid.). The main distinctive feature between Evoked and Inferable entities is that "while evoked referents are preceded in a discourse by a direct antecedent (previous mention), inferable referents are identifiable via inference from an indirect antecedent" (Howard, 2002, p.47). The complexity of Inferables (I) is that they are not clearly tied to a given status. In other words, they can be either discourse-old or discourse-new and can also be either hearer-old or hearer-new. Following is an example:

6) I got on a bus yesterday and the driver was drunk.

The referent represented by the NP 'the driver' is inference from the previous mention of the word 'a bus' which entails that 'buses have drivers'. This is already present and active in the hearer's consciousness. The NP 'a bus' is Brand New.

\section{6-2- Pierrehumbert's Autosegmental Metrical Approach:}

Unlike the British approach to intonation analysis, that deals with intonation holistically, the American notion treats intonation hierarchically. In other words, it regards contours as "a sequence of levels or targets' (Levis \& Wichmann, 2015, p.141). While words in the English language are associated with a simple lexical stress pattern that assigns one syllable the greatest prominence, it is the relative prominence of words in an utterance that determines its intonational contour. Autosegmental Metrical approach (henceforth AM), a system presented by Janet Pierrehumbert (1980), marks a further development. AM framework describes intonational pitch contours as a sequence of two 
basic tonal units, namely pitch accents and edge tones, which further include two subtypes, namely phrase accents and boundary tones. Each will be discussed in details below:

\section{6-2-1- Pitch accent:}

Pitch accents specify the relative prominence assigned to words in an utterance. They are intonational movements that are associated with the stressed lexical items. Hence, they render lexical words prominent or accented. In other words, pitch accents "align certain lexical items in an utterance with relative minima and maxima in the fundamental frequency contour (fo)" (Ibid.). There are SIX pitch accents in the model: TWO simple basic monotonal accents, $\left(\mathrm{H}^{*}\right)$ and $\left(\mathrm{L}^{*}\right)$, and FOUR bitones, $\left(\mathrm{H}^{*}+\mathrm{L}\right),\left(\mathrm{H}+\mathrm{L}^{*}\right),\left(\mathrm{L}^{*}+\mathrm{H}\right),\left(\mathrm{L}+\mathrm{H}^{*}\right)$.

\section{6-2-1- Monotones \& Bitones:}

$\mathrm{H}^{*}$ accent on a specific word means that "a tone occurring high in the speaker's pitch range whose peak occurs on the lexically stressed syllable of the word" (Ibid.). The asterisk $(*)$ indicates that the tone is aligned with a stressed syllable.

$\mathrm{L}^{*}$, on the other hand, means that the word is uttered with a tone which occurs low in the speaker's pitch range and is aligned with the stressed syllable.

In reference to the complex bitones, they are sequence of two tones; the tone marked with the asterisk is aligned with the lexically stressed syllable. The other tone represents the rising or falling nature of the accent.

\section{6-2-2- Edge tones:}

They are intonational movements assigned to the end of prosodic phrases. They are divided into two types: phrase accent and boundary tone. Phrase accents are intonational movements that mark the end of an intermediate phrase. Such a movement is placed on the last pitch accent of the intermediate phrase. The phrase accent can be High $(\mathrm{H})$ or Low (L). An intermediate phrase consists of "one or more pitch accents, which 


\section{Yasmin M. Al-Sayed}

are aligned with stressed syllables (syllable alignment is indicated by *) on the basis of the metrical pattern of the text, plus a simple $\mathrm{H}$ or $\mathrm{L}$ which characterizes the phrase accent" (Hirschberg et al., , p.636).

Boundary tones mark the end of an intonational phrase as High ( $\mathrm{H} \%)$ or Low (L\%). The symbol (\%) indicates the boundary tone. Intonational phrases consist of "one of more such intermediate phrases plus a boundary tone ... It falls exactly at the phrase boundary" (Ibid.).

Pierrehumbert \& Hirschberg (1990) assign discourse functions to the particular tones. Given/New information is intonationally marked through the employment of pitch accent. "Pitch accents convey information about the status of the individual discourse referents, modifiers, predicates, and relationships specified by the lexical items with which the accents are associated" (Pierrehumbert \& Hirschberg, 1990, p.286). New information is marked by $\left(\mathrm{H}^{*}\right)$ (high tone aligned with a stressed syllable), whereas given information is represented by either $\left(\mathrm{L}^{*}\right)$ (low tone aligned with a stressed syllable) or lack of accent (deaccentuation). With regard to inferables, they are represented by a falling pitch contour.

\section{7- Analysis \& Findings:}

\section{7-1- The story:}

The short story "A Pair of Silk Stockings" is written by the feminist writer Kate Chopin in 1896 and published in 1897. The main character, Mrs. Sommers, serves as both the protagonist and the antagonist. Her personality and her life are full of contradictions. Diverse themes are discussed in the story: women versus their society, materialism, the self and self sacrifice.

Mrs. Sommers is a wife and mother. Her family is poor and she somehow has fifteen dollars which are considered a large amount of money. She plans to spend the money buying some items of clothing for her children. However, on that particular day, Mrs. Sommers forgot about her children needs and got tempted by her personal needs. Throughout the story, Mrs. Sommers is beautifully portrayed as a woman struggling between two different roles: her role as a mother and her role towards 
herself. The story's ambiguous ending imolies that it is a continuing struggle of women of that period.

\section{7-2- The analysis:}

The narrative discourse being examined is entitled "A Pair of Silk Stockings" by Kate Chopin. The oral narrative of the short story consists of 114 sentences. The oral narrative is said by a woman voice. The sound file is uploaded in Praat. The analysis is conducted using Praat software as follows:

1) The text is segmented into sentences. Each sentence is further divided into four tiers: the sentence tier, the intermediate phrases (IPs), the referents, and the pitch accent. The principle of segmentation into (IPs) is the pauses and phrase-final syllable lengthening taking place between the utterances.

2) In each intermediate phrase, the referents (entities), noun phrases that carry information, are labeled as $(\mathrm{BN}),(\mathrm{E})$, or (I) according to Prince's taxonomy.

3) Each referent is assigned a pitch accent through manually examining the pitch contour.

4) If the entity carries no pitch accent, i.e. deaccented, it is denoted by the word 'unaccented'. Unaccented words are distinguished from accented ones in terms of loudness, duration, and prominence.

The story is divided into THREE sections: Introduction, Development, and Resolution. Each section will be analyzed in terms of the information status of the referents and the assigned pitch accents.

\section{First, Orientation:}

This section comprises 21 sentences, from sentence 1 through sentence 21. It introduces the participants in the action, namely, the persons, the time, and the place. The narrator aims to provide answer to the listener's question of 'How did this event come about?' Table (1) shows the information status of the referents along with their number: 
Yasmin M. Al-Sayed

\begin{tabular}{|c|c|}
\hline Information Status & Number of Referents \\
\hline Brand New (BN) & 46 \\
\hline Inferable (I) & 6 \\
\hline Evoked (E) & 30 \\
\hline Total & 82 \\
\hline
\end{tabular}

Table (1): The Status and Number of Information Referents in the Introduction

(32) Brand New $(\mathrm{BN})$ referents are assigned $\left(\mathrm{H}^{*}\right)$ pitch accent. The referents represent information that is necessary for the listener's comprehension of the narrative as well as the motifs of the principal character. For instance, some referents introduce information related to the current state of the principal character and the amount of money that she owns: 'the unexpected owner', 'fifteen dollars' (sentence 1).

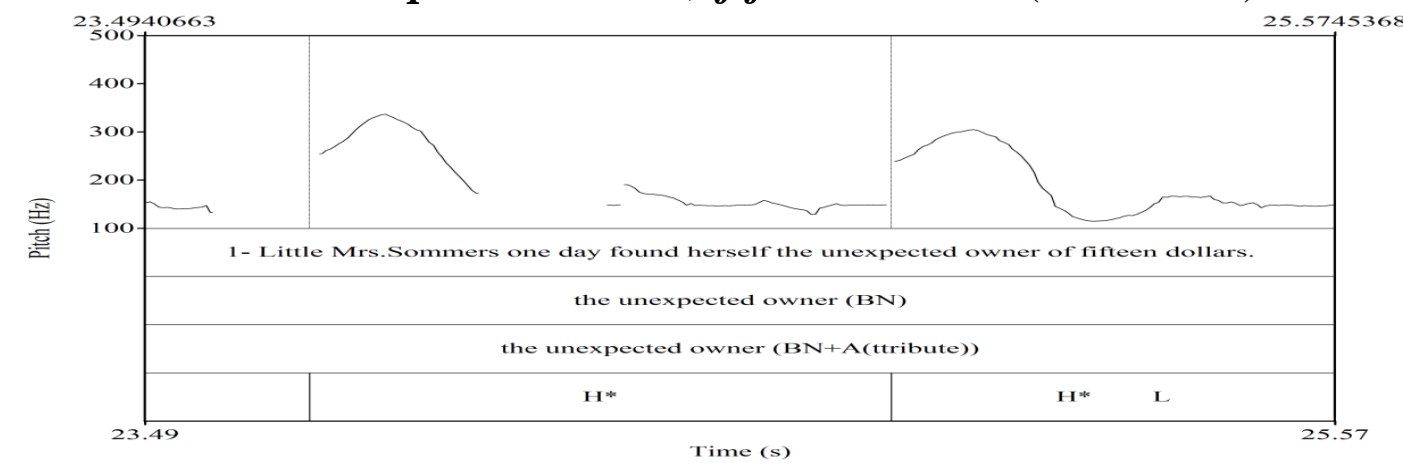

Figure (1): Pitch contour of the Brand New Referent "the unexpected owner'

In addition, other referents show how Mrs. Sommers intends to spend the money on what her children would benefit the most. Such referents include 'her choices', 'shoes', 'another dress', 'cloth', 'new shirts', 'new stockings'. All are referents that the listener needs to create through mentally visualizing the discourse model. 


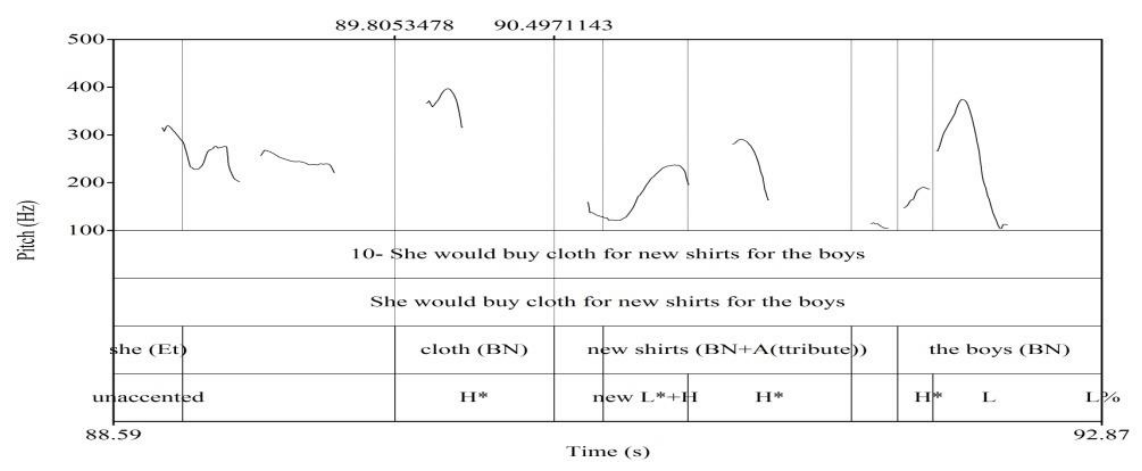

Figure (2): Pitch Contour of Brand New Referent "cloth"

Also, there are Brand New referents that provide the listener with essential information about the main character's emotional and mental state after having the amount of money like 'a feeling of importance'. Other Brand New referents draw the listener's attention to the contrast between Mrs. Sommers' past and present condition such as 'better days', 'the needs of the present'.

Through uttering them with $\left(\mathrm{H}^{*}\right)$ pitch accent, the story teller manages to shed light on Mrs. Sommers' organized, repressed nature as well as her readiness to sacrifice herself for her children. The items that are marked $\left(\mathrm{H}^{*}\right)$ are "to be added to H's mutual belief space" (Pierrehumbert \& Hirschberg, 1990, p.290). It is noted that such referents are followed by (L) phrase accent, which is a distinguishing mark of declarative statements that represent the speaker's intention to convey information.

(7) referents are assigned $\left(\mathrm{L}+\mathrm{H}^{*}\right)$. Examples include 'the question of investment' (sentence 4), 'her daughter Meg' (sentence 11). Such referents are preceded by background information that paves the way for the listener for their introduction and integration into his mental model. For example, before the mention of 'her daughter Meg', the storyteller mentioned other family members and their needs.

The speaker's goal is to relate such referents to a space of possible alternatives and distinguishing them as a means of establishing them in the listener's consciousness. According to Pierrehumbert (2000), "the $\mathrm{L}+\mathrm{H}$ accents mark information which is selected from a small domain of alternatives, with the $\mathrm{L}+\mathrm{H}^{*}$ marking an add" (p.24). 


\section{Yasmin M. Al-Sayed}

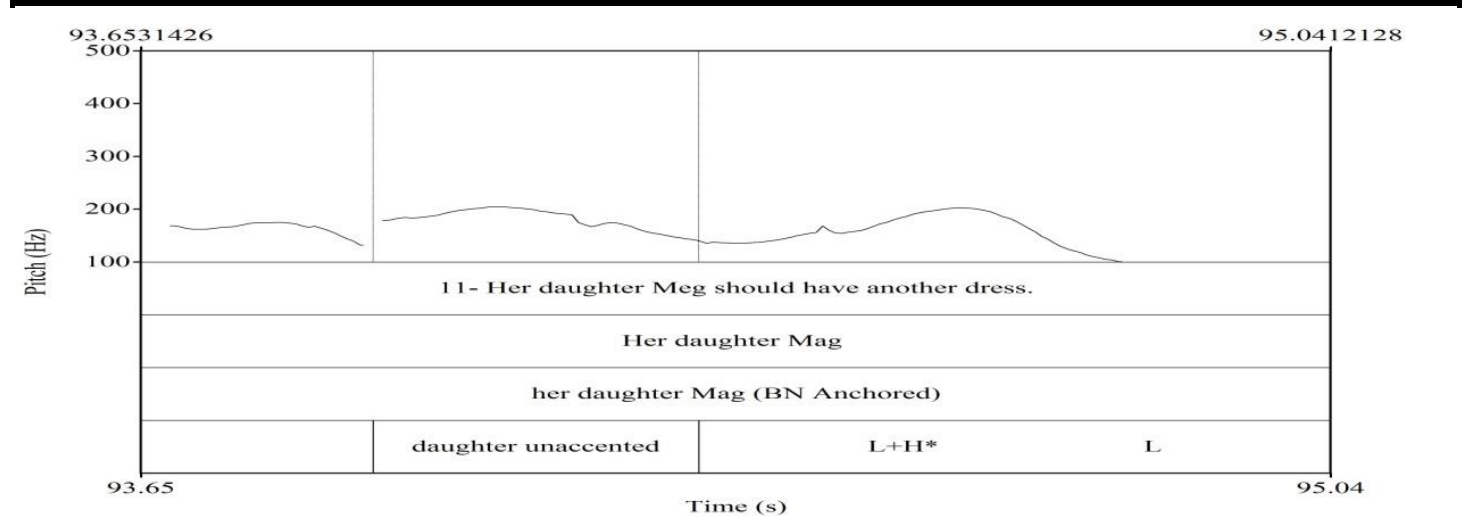

Figure (3): Pitch Contour of Brand New Referent "her daughter Meg"

Evoked referents are mostly pronouns or repeated noun phrases. They refer back to previously mentioned entities in the discourse history. They stand for an already formed part of the listener's mental model. In other words, they are both discourse-old and hearer-old. An example is the pronoun 'her' (sentence 13) which refers back to Mrs. Sommers that was mentioned earlier.

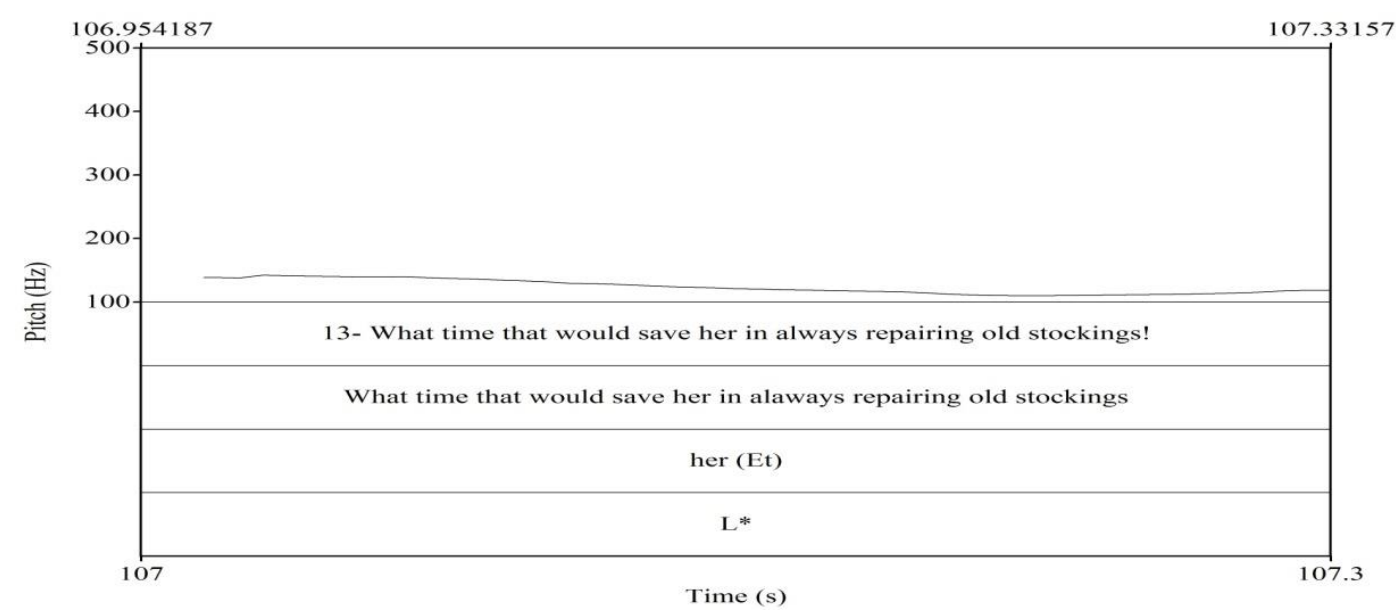

Figure (4): Pitch Contour of Evoked Referent "her"

Evoked referents are either deaccented or assigned ( $\left.\mathrm{L}^{*}\right)$ pitch accent. Evoked entities are used to facilitate the sequence of events and to help the listener focus on more new referents.

The inferable referents are inferred from previous propositions. In other words, they presented information connected to previous sentences. For example, in sentence (12), 'And still there would be enough left for new stockings...', 'enough' is inferred as referring to adequate amount of money. This can be understood from previous sentences which mention how Mrs. Sommers will spend the money, 'She would buy cloth for new shirts for the boys' (sentence 10), 'Her daughter Meg should have another dress' (sentence 11). Such referent is inferred through understanding the character's intention from previous propositions. The 
speaker's aim is to bring them in the listener's focus as they assist in reconstructing elements of the story.

The inferable referents are assigned $\left(\mathrm{H}^{*}\right)$ or $\left(\mathrm{L}+\mathrm{H}^{*}\right)$ or unaccented. According to Pierrehumbert \& Hirschberg (1990), (L+H) accents serve to contrast the target with a set of alternatives. The speaker's purpose for employing this accent is to draw the listener's attention to the contrast between the main character's life and normal life of normal people. The contrast is between what the listener finds reasonable in real world and what he/she encounters in the discourse model. It is against the listener's expectations that this small amount of money would be 'enough' to buy more stuff.

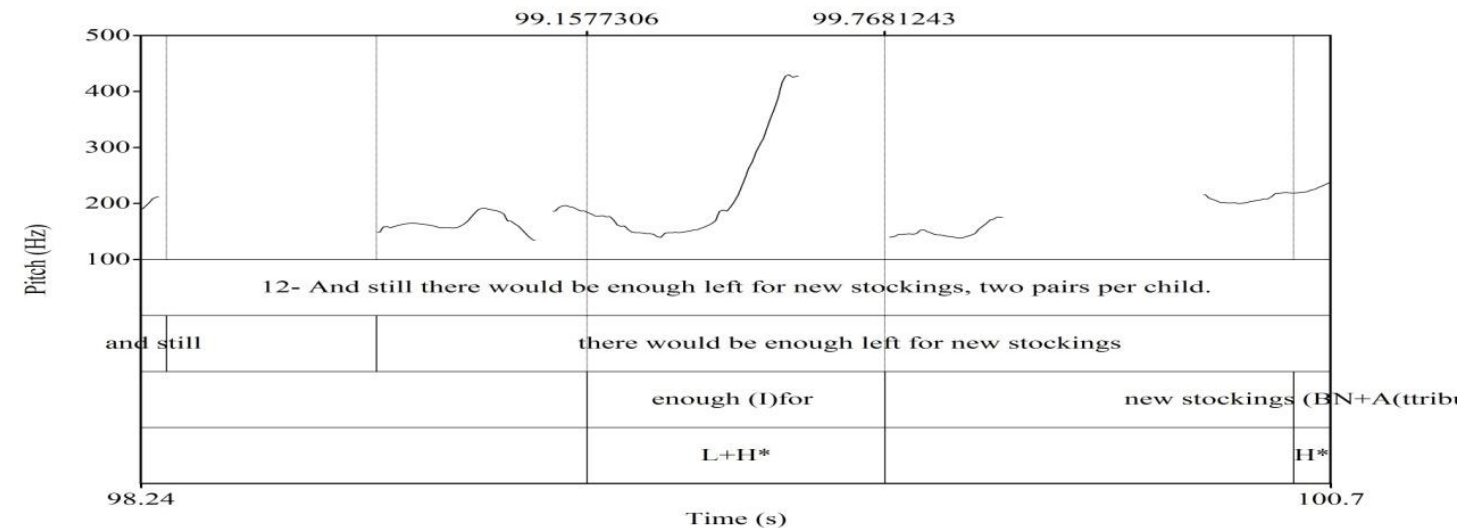

Figure (5): Pitch Contour of Inferable 'enough'

Second, Development: This section stretches out from sentence (22) up to sentence (110). (324) referents are identified as carrying information of different types. They are classified as shown in the following table:

\begin{tabular}{|c|c|}
\hline Information Status & Number of Referents \\
\hline Brand New (BN) & 94 \\
\hline Inferable (I) & 65 \\
\hline Evoked (E) & 165 \\
\hline Total & 324 \\
\hline
\end{tabular}

Table (2): The Status and Number of Information Referents in the Introduction

This section of the story answers the question of "What did Mrs. Sommers do with the amount of money she got?" which is the logical development of the presented information in the introduction section. The section unfolds the places and names of objects that she bought. Likewise, the section portrays Mrs. Sommers' feelings towards this unique experience. 


\section{Yasmin M. Al-Sayed}

The Brand New referents stand for the NPs that denote the places and her feelings. Either case, the referents are both discourse-new and hearernew. Examples include 'the large department store', 'strength', 'courage', 'silk stockings', and so forth. (62) referents are assigned $\left(\mathrm{H}^{*}\right)$ pitch accent. They are marked by extra loudness, duration, and prominence over the stressed syllable.

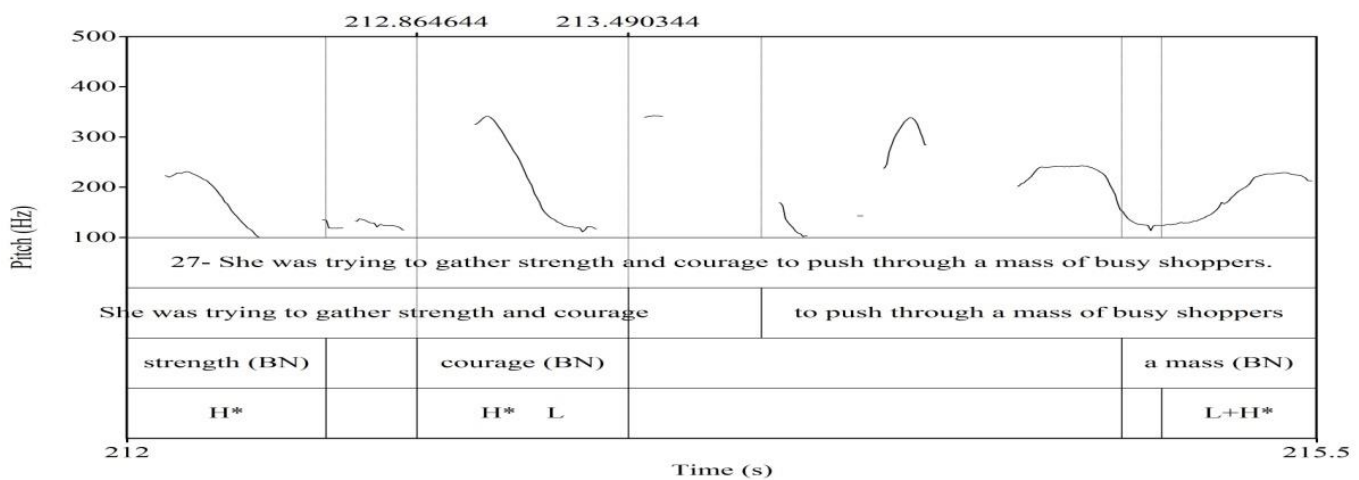

Figure (6): Pitch Contour of Brand New Referents 'strength' \& 'courage'

The narrator wants these referents to be present in and added to the listener's mutual beliefs. $\left(\mathrm{H}^{*}\right)$ pitch accent is combined with $\mathrm{L}$ phrase accent to convey information. The remaining BNs are assigned $\left(\mathrm{L}+\mathrm{H}^{*}\right)$ to serve illuminating the contrast between the narrative world and the real world.

All the Evoked referents are discourse-old and hearer-old. They refer back to the principal character (Mrs. Sommers) or to other entities like the previously mentioned objects or places. All entities are assigned either $\left(\mathrm{L}^{*}\right)$ pitch accent in the pitch range or deaccented. For example, in sentence (33), 'A young girl ... asked herif she wished to examine...', both of the pronouns 'her' and 'she' refer back to the main character 'Mrs. Sommers'.

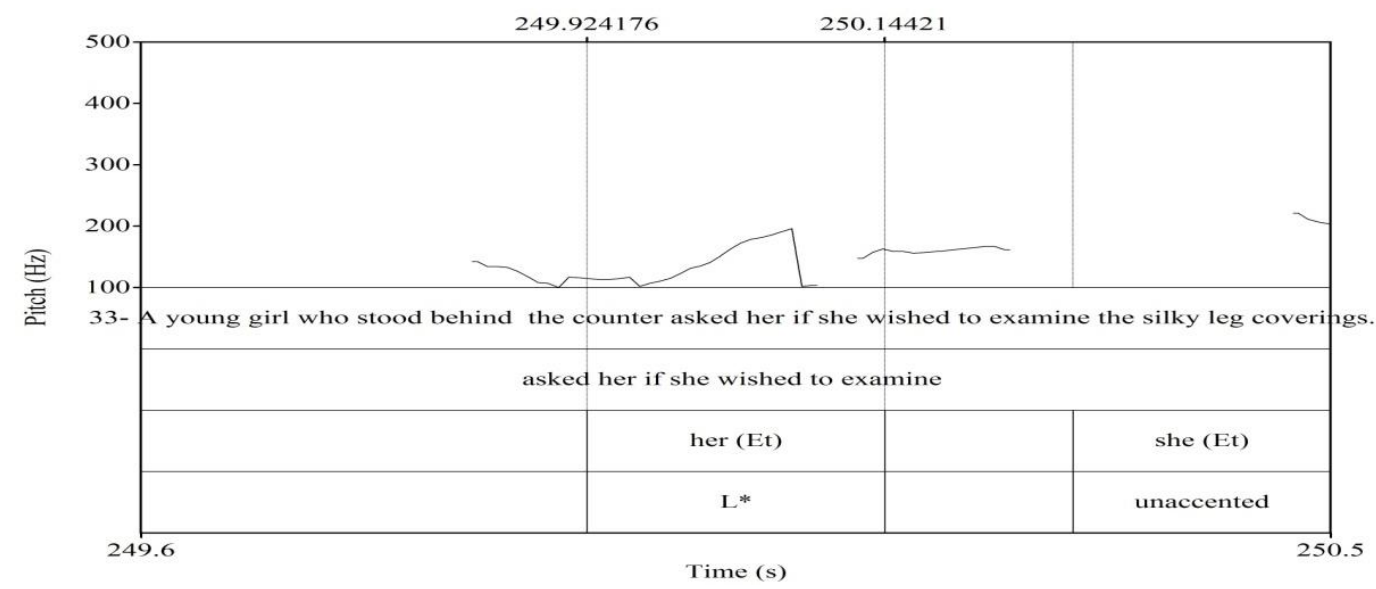

Figure (7): Pitch Contour of Evoked Referents 'her' \& 'she'

With regard to inferable entities, they are "pieces of information about events, relations ... that the reader adds to the information that is explicitly presented in discourse" (Baretta et al., 2009, p.138). They 
establish a relation in the listener's mind between old (mentioned) and new information. The basic sources of inference are the explicit statements and the listener's general knowledge. For example, in sentence (36), 'Now she used both hands, holding the stockings up ...', the listener is familiar with the fact that hands are a part of any human body, including Mrs. Sommers'.

In studying the pitch accent of inferred items, (16) referents were assigned either $\left(\mathrm{H}^{*}+\mathrm{L}\right)$ or $\left(\mathrm{L}+\mathrm{H}^{*}\right)$. According to Pierrehumbert \& Hirschberg (1990), "S uses H+L accents to indicate that support for the open expression's instantiation with the accented items should be inferable by $\mathrm{H}$ from his representation of the mutual beliefs" (p.297). Thus, after the narrator tells the listener new information about the places that Mrs. Sommers visited and the items that she bought, the listener is required to fill in the gaps of the information using inference. Examples include the following:

Sentences (26) and (27): When she arrived at the large department store, she sat in front of an empty counter. She was trying to gather strength and courage to push through a mass of busy shoppers". The italicized referents are all Brand New. The underlined referent is mentioned for the first time. The listener needs to create a logical relation that relate the referents.

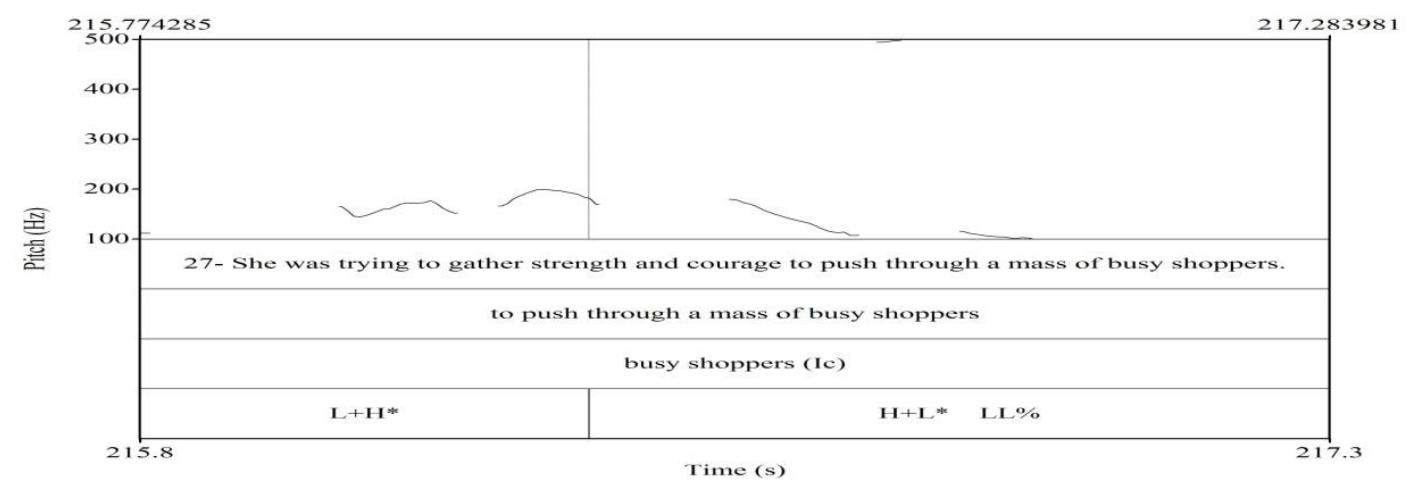

Figure (8): Pitch Contour of The Inferable Referent 'busy shoppers'

It is noted that straightforward inferred items, such as containing inferables (Ic), are marked ( $\left.\mathrm{L}^{*}\right)$ or deaccented. An example is sentences (65) and (66): 'It was long time since Mrs. Sommers had been fitted with gloves. When she had bought a pair...' The referent 'pair' is inferred by the listener as 'a pair of gloves'. It is known that gloves come in pairs. 


\section{Yasmin M. Al-Sayed}

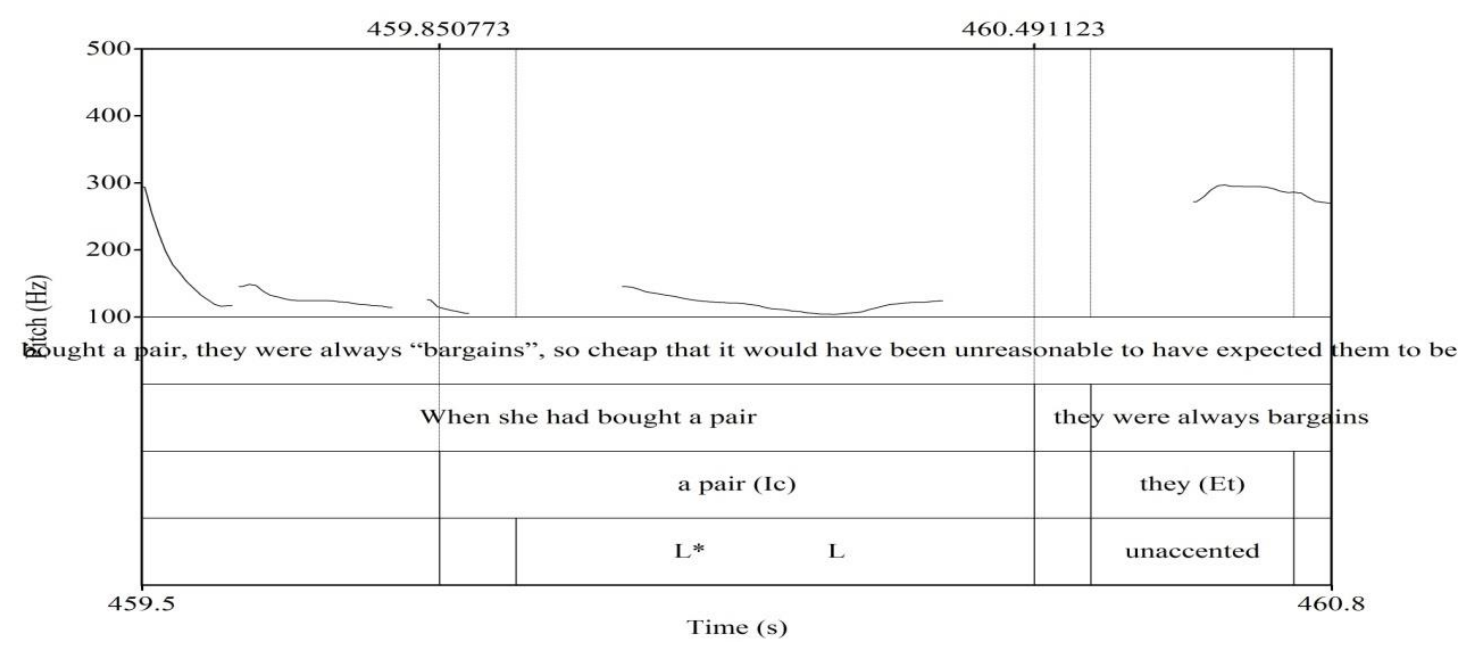

Figure (9): Pitch Contour of the Inferable Referent 'a pair'

(15) inferred referents are assigned $\left(\mathrm{H}^{*}\right)$ pitch accent. The narrator chooses to focus on these referents because they are significant to pursuing the narrative and comprehending the context. For example, in sentence (28), 'She rested her hand upon the counter', the referent 'her hand is inferred and assigned $\left(\mathrm{H}^{*}\right)$. The mentioned hand is made prominent because it is the means by which Mrs. Sommers gets the feelings of the silk stockings. Upon this incident, the incidents develop.

In reference to The Evoked referents, all are discourse-old and hearerold. They serve as a means of linking the listener's thoughts about the story. They are represented either by pronouns or repeated NPs. All entities are assigned $\left(\mathrm{L}^{*}\right)$ or deaccented.

Third, Resolution:

The last section of the story starts from sentence (111) through (115). This section marks the end of the story and terminates the actions. It provides answer to the listener's question "What finally happened?" The following table shows the identified referents:

\begin{tabular}{|c|c|}
\hline Information Status & Number of Referents \\
\hline Brand New (BN) & 6 \\
\hline Inferable (I) & 1 \\
\hline Evoked (E) & 9 \\
\hline Total & 16 \\
\hline
\end{tabular}

Table (3): The Status and Number of Information Referents in the Resolution

As approaching the end of the story, only (6) Brand New referents refer to how Mrs. Sommers finished her day, her feelings, and the participants in the action. A man is a secondary character that is presented 
only to give the listener an idea about Mrs. Sommers' feelings towards the end of her amazing day. The remaining referents serve portray her feelings. For example, in sentence (113), the referent 'her expression' is Brand New. All the referents are assigned $\left(\mathrm{H}^{*}\right)$ pitch accent.

One inferred referent is identified in sentence (112), 'A man with sharp eyes...' the listener infers that the eyes belong to the man. The

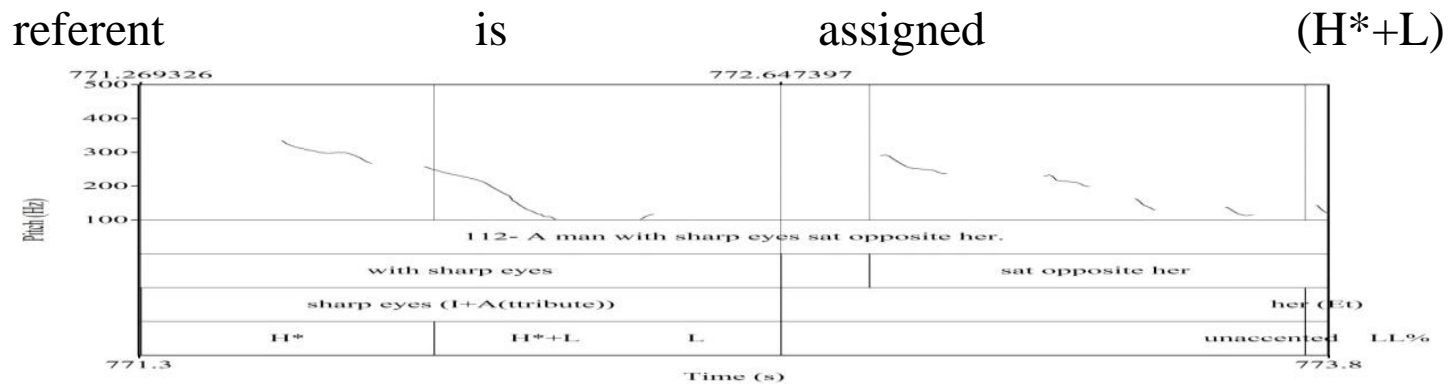

Figure (10): Pitch Contour of Inferable Referent 'sharp eyes'

As was observed in the last two sections, Evoked referents are either pronouns or repeated NPs that refer back to already mentioned entities. The entities are assigned either $\left(\mathrm{L}^{*}\right)$ or deaccented at all.

\section{7-2- Findings:}

The analysis demonstrated that the short story under analysis, as representative of the narrative genre of discourse, has a certain structure of information. It has "a skeleton of categories or slots around which the details ... are built" (Snow \& Goldfield, 1981, p.128). The categories of information, i.e. new, evoked or inferred, play a role in conveying the informative content of discourse. Thus, for example, BNs provide the listener with enough information about item labels in the narrative. The NPs identified as BN refer the principal character of the story, secondary characters, places that she visited, or objects she bought and enjoyed. The majority of BNs are attributed (i.e. preceded by an adjective). This is one way of conveying item elaboration.

Throughout the short story, it is noted that BNs precede Evoked or inferred referents. This strategy is adopted by the narrator as the introduction of new referents first facilitated narrative discourse comprehension and memorization. Also, it enables the listener to integrate them immediately "into an already constructed model of underlying event structure" (Ohtsuka \& Brewer, ,p.6). Likewise, the evoked referents are used abundantly in referring back the previously mentioned antecedents. Thus, the listener can attach the new information to them.

With regard to intonation, represented specifically by the narrator's choice of pitch accents to highlight information-carrying referents, it 


\section{Yasmin M. Al-Sayed}

plays a significant role in adding specific interactional significance. It is explicitly used by the narrator to convey meanings to the listener who does not have access to the written text and the only medium of transmission is the speech and its intonational features. "The intonational divisions speakers make in their utterances are not grammatically motivated; rather they are motivated by a need to add moment-bymoment situationally specific, intonationally conveyed meanings to particular words or groups of words" (Coulthard \& Brazil, 1981, p.97).

\section{8- Conclusion:}

The present paper sets out to examine the relationship between intonation and the information status of discourse referents using audio speech. The study focuses on one aspect of intonational features, namely, the pitch accent. Also, it focuses on one aspect of information structure, namely, the dichotomy given/new information. For this purpose, Autosegmental Metrical Theory and Prince's Assumed Familiarity Theory are adopted as the theoretical framework.

The audio of the short story "A Pir of Silk Stockings", by American writer Kate Chopin, is the data analysed in terms of the intonational marking of its information structure. Most of the results of study support claims made previously in the literature. They are:

1) New information tends to be accented.

2) Given information is most likely to be assigned low accent or to be deaccented.

3) Inferables are marked by rising-falling accent $\left(\mathrm{H}^{*}+\mathrm{L}\right.$ or $\left.\mathrm{H}+\mathrm{L}^{*}\right)$.

The selection of narrative discourse, represented by the short story, as data of analysis and investigation proved efficient for a diversity of reasons. First, the situations and episodes presented in narrative have a strong resemblance with everyday experiences. Second, the structure of narrative discourse and the way of presenting information facilitates and accelerates the comprehension mechanisms. Third, similar to everyday discourse, it is acknowledged that narrative presents layers of information beyond its explicit spoken or written text. It relies on background world knowledge and inferences to go beyond the explicit information. These reasons render narrative discourse better suited candidate for the analysis of the present paper. 


\section{References}

Baretta, L., Tomitch, L. M., MacNair, N., Lim, V. K. \& Waldie, K. E. (2009). Inference making while reading narrative and expository texts: An ERP study. Psychology \& Neuroscience, 2 (2), 137-145.

Boersma, P. \& Weenink, D. (2013). Praat: Doing phonetics by computer (Version 5.3.51) [Computer program]. Retrieved from http://www.praat.org/

Brazil, D. (1980). Discourse intonation and language teaching. London: Longman.

Brazil, D. (1994). Pronunciation for advanced learners of English teacher's book and student's book. Cambridge University Press.

Bruner, J. (1986). Actual minds, possible worlds. Cambridge, MA: Harvard University Press.

Cauldwell, R. (2002). Streaming speech: Listening and pronunciation. Birmingham: Speechinaction.

Chafe, W. L. (1976). Givenness, contrastiveness, definiteness, subjects, topics, and point of view. In C. Li (Ed.), Subject and topic (pp. 25-55). New York: Academic Press.

Chafe, W. L. (1980). The pear stories: Cognitive, cultural, and linguistic aspects of narrative production. Norwood, N.J.: Ablex.

Chafe, W. L. (1994). Discourse, consciousness, and time. Chicago, IL: University of Chicago Press.

Clark, H. H. \& Haviland, S. E. (1977). Comprehension and the given-new contract. In R. O. Freedle (Ed.), Discourse production and comprehension. Norwood, New Jersey: Ablex.

Coulthard, M. \& Brazil, D. (1981). The place of intonation in the description of interaction. In Tannen, D. (ed.), Georgetown University Round Table on Language and Linguistics (pp.94-112). Washington, D.C.: Georgetown University Press.

Couper-Kuhlen, E. (2001). Intonation and discourse: Current views from within. In D. Schiffrin, D. Tannen \& H. Hamilton (Eds.), The handbook of discourse analysis (pp. 13-34). USA: Blackwell Publishers.

Couper-Kuhlen, E. \& Selting, M. (Eds.) (1996). Prosody in conversation. Cambridge University Press.

Crystal, D. (1995). The Cambridge encyclopedia of the English language. Cambridge University Press.

Gubrium, J. F. \& Holstein, J. A. (2007). Narrative ethnography. In S. N. Hesse-Biber \& P. Leavy (Eds.), Handbook of emergent methods (pp. 241-254). New York: Guilford Press.

Hadley, G. S. (1996). A discourse approach to intonation: Can it work in Japan? Niigata Tudies in Foreign Languages and Cultures, 2, 115-125.

Halliday, M. A. K. (1967). Notes on transitivity and theme in English (part 2). Journal of Linguistics 3, pp. 199-244.

Halliday, M. A. K. (1973). Explorations of the functions of language. London: Edwin Arnold.

Haviland, S. \& Clark, H. (1974). What's new? Acquiring new information as a process in comprehension. Journal of Verbal Learning and Verbal Behavior, 13 , pp. 512-521. 


\section{Yasmin M. Al-Sayed}

Heusinger, K. V. (1999). Intonation and information structure. Habilitationsschrift. Universitat Konstanz.

Hirschberg, J., Litman, D., Pierrehumbet, J. \& Ward, G. Intonation and the intentional structure of discourse. Natural Language, , pp. 636-639.

Howard, D. E. (2002). Continuity and given-new status of discourse referents in Adzera oral narrative (master's thesis). The University of Texas, Arlington.

Hyvarinen, M. (2007). Analyzing narratives and story-telling. In Pertti Alasuutari, Leonard Bickman \& Julia Brannen (Eds.), The SAGE handbook of social research methods (pp. 447-460). Los Angeles: SAGE.

Karpus, L. B. (2012). Intonation of English persuasive discourse. Transactions of Gogol State University of Nizhyn, pp. 96-101. Retrieved from lib/ndu/edu.ua

Karttunen, L. (1971). Discourse Referents. In McCawley, J. (Ed.), Syntax and semantics 7: Notes from the linguistic underground (pp. 363-386). New York: Academic Press.

Kinneavy, J. (1971). A theory of Discourse: The aims of discourse. Englewood Cliffs, NJ: Prentice.

Ladd, D. R. (2001). Intonational universals and intonational typology. In Haspelmath, M., Konig, E., Oesterreicher, W. \& Raible, W. (Eds.), Language typology and language universals: An international handbook (pp.1380-1390, vol. 2). New York: Walter de Gruyter.

Levis, J. \& Wichmann, A. (2015). English intonation: Form and meaning. In Reed, M. \& Levis, J. M. (Eds.), The handbook of English pronunciation (pp.139-155). John Wiley \& Sons, Inc.

Lieshout, P. V. (2003). PRAAT short tutorial: A basic introduction. Retrieved from http://web.stanford.edu/dept/linguistics/corpora/material/PRAAT_workshop_ manual_V421.pdf

Nolan, F. (2006). Intonation. In Aarts, B. \& McMahon, A. (Eds.), The handbook of English linguistics (pp. 433-457). Malden, MA: Blackwell Publishing Ltd.

Noordman, Leo G. M. \& Vonk, W. (2015). Psychology of inferences in discourse. In J. D. Wright (Ed.), International encyclopedia of social and behavioral sciences (pp. 37-44). New York: ELSEVIER.

Ochs, E. \& Capps, L. (2001). Living narrative: Creating lives in everyday storytelling. Cambridge, MA: Harvard University Press.

O'Grady, G. (2016). Given/new: What do the terms refer to? English Text Construction 9:1, pp. 9-32.

Ohtsuka, K. \& Brewer, W. F. (1992). Discourse organization in the comprehension of temporal order in narrative texts. Discourse Processes, 15, pp. 317-336.

Pierrehumbert, J. B. (1980). The phonology and phonetics of English intonation (Unpublished Doctoral Dissertation). Massachusetts Institute technology, Massachusetts.

Pierrehumbert, J. B. (2000). Tonal elements and their alignment. In M. Horne (Ed.), Prosody: Theory and experiment (pp. 11-36). London: Kluwer.

Pierrehumbert, J. \& Hirschberg, J. (1990). The meaning of intonational contours in the interpretation of discourse. In P. R. Cohen, J. Morgan \& M. E. Pollack (Eds.), Intentions in communication (pp. 271-311). Cambridge, MA: MIT Press.

Prevost, S. A. (1995). A semantics of contrast and information structure for specifying intonation in spoken language generation (Doctoral Dissertaion). University of Pennsylvania, Philadelphia. (PA 19104-6228). 
Prince, E. F. (1981). Toward a taxonomy of given/new information. In P. Cole (Ed.), Radical pragmatics (pp. 223-255). New York: Academic Press

Prince, E. F. (1992). The ZPG letter: Subjects, definiteness, and information status. In W. C. Mann \& S. A. Thompson (Eds.), Discourse description: Diverse linguistic analyses of a fund-raising text (pp. 295-325). Amsterdam: John Benjamins.

Roach, P. (1983). Functions of Intonation 2. In English phonetics and phonology (pp. 143-150). Reino Unido: Cambridge University Press.

Roach, P. (1992). Introducing phonetics. London: Penguin.

Snow, C. F. \& Goldfield, B. A. (1981). Building stories: The emergence of information structures from conversation. In Tannen, D. (ed.), Georgetown University Round Table on Language and Linguistics (pp.127-141). Washington, D.C.: Georgetown University Press.

Steedman, M. \& Kruijff-Korbayova, I. (2001). Two dimensions of information structure in relation to discourse structure and discourse semantics. In KruijffKorbayova, I. \& Steedman, M. (Eds.), Information structure, Discourse structure, and discourse semantics: Workshop Proceedings (pp.1-10). 13 ${ }^{\text {th }}$ European Summer School in Logic, Language, and Information.

Vaissiere, J. (2004). Perception of intonation. In Pisoni, D. B. \& Remez, R. E. (Eds.), Handbook of speech perception. Oxford: Blackwell.

van Dijk, T. (1976). Narrative macro-structures. PTL: A Journal for Descriptive Poetics and Theory of Literature, pp. 547-568.

Ward, G. \& Birner, B. J. (2001). Discourse and information structure. In D. Schiffrin, D. Tannen \& H. Hamilton (Eds.), The handbook of discourse analysis (pp. 119-137). USA: Blackwell Publishers. 


\section{$\underline{\text { Appendix (1) }}$}

Our story today is called "A Pair of Silk Stockings." It was written by Kate Chopin. Here is Barbara Klein with the story.

\section{A Pair of Silk Stockings}

Little Mrs. Sommers one day found herself the unexpected owner of fifteen

dollars.

It seemed to her a very large amount of money. The way it filled up her worn money holder gave her a feeling of importance that she had not enjoyed for years.

The question of investment was one she considered carefully. For a day or two she walked around in a dreamy state as she thought about her choices. She did not wish to act quickly and do anything she might regret. During the quiet hours of the night she lay awake considering ideas.

A dollar or two could be added to the price she usually paid for her daughter Janie's shoes. This would guarantee they would last a great deal longer than usual. She would buy cloth for new shirts for the boys. Her daughter Mag should have another dress. And still there would be enough left for new stockings - two pairs per child. What time that would save her in always repairing old stockings! The idea of her little family looking fresh and new for once in their lives made her restless with excitement.

The neighbors sometimes talked of the "better days" that little Miss Sommers had known before she had ever thought of being Mrs. Sommers.

She herself never looked back to her younger days. She had no time to think about the past. The needs of the present took all her energy. Mrs. Sommers knew the value of finding things for sale at reduced prices. She could stand for hours making her way little by little toward the desired object that was selling below cost. She could push her way if need be. 
Intonational Marking of Given/New Information in Oral Storytelling An Analysis of Intonation of Information Structure in Narrative Discourse

\begin{tabular}{lcccccc}
\hline But that day she was tired and a little bit weak. \\
She & had & eaten & a & light & meal- no! \\
She & thought & & about & her & day.
\end{tabular}

Between getting the children fed and the house cleaned, and preparing herself to go shopping, she had forgotten to eat at all! When she arrived at the large department store, she sat in front of an empty

counter.

She was trying to gather strength and courage to push through a mass of busy shoppers.

She rested her hand upon the counter.

She

wore

no

gloves.

She slowly grew aware that her hand had felt something very pleasant to touch. She looked down to see that her hand lay upon a pile of silk stockings. A sign nearby announced that they had been reduced in price. A young girl who stood behind the counter asked her if she wished to examine the silky leg coverings. She smiled as if she had been asked to inspect diamond jewelry with the aim of purchasing it. But she went on feeling the soft, costly items. Now she used both hands, holding the stockings up to see the light shine through them.

Two red marks suddenly showed on her pale face. She looked up at the shop girl. "Do you think there are any size eightsand-a-half among these?" There were a great number of stockings in her size. Mrs. Sommers chose a black pair and looked at them closely.

"A dollar and ninety-eight cents," she said aloud. "Well, I will buy this pair." She handed the girl a five dollar bill and waited for her change and the wrapped box with the stockings. What a very small box it was! It seemed lost in her worn old shopping bag.

Mrs. Sommers then took the elevator which carried her to an upper floor into the ladies' rest area. In an empty corner, she replaced her cotton stockings for the new silk ones. For the first time she seemed to be taking a rest from the tiring act of thought. She had let herself be controlled by some machine-like force that directed her actions and freed her of responsibility. 


\section{Yasmin M. Al-Sayed}

How good was the touch of the silk on her skin! She felt like lying back in the soft chair and enjoying the richness of it. She did for a little while. Then she put her shoes back on and put her old stockings into her bag.

Next, she went to the shoe department, sat down and waited to be fitted. The young shoe salesman was unable to guess about her background. He could not resolve her worn, old shoes with her beautiful, new

She tried on a pair of new boots.

stockings.

She held back her skirts and turned her feet one way and her head another way as she looked down at the shiny, pointed boots. Her foot and ankle looked very lovely. She could not believe that they were a part of herself. She told the young salesman that she wanted an excellent and stylish fit. She said she did not mind paying extra as long as she got what she desired.

After buying the new boots, she went to the glove department. It was a long time since Mrs. Sommers had been fitted with gloves. When she had bought a pair they were always "bargains," so cheap that it would have been unreasonable to have expected them to be fitted to her hand. Now she rested her arm on the counter where gloves were for sale. A young shop girl drew a soft, leather glove over Mrs. Sommers's hand. She smoothed it down over the wrist and buttoned it neatly. Both women lost themselves for a second or two as they quietly praised the little gloved hand.

There were other places where money might be spent. A store down the street sold books and magazines. Mrs. Sommers bought two costly magazines that she used to read back when she had been able to enjoy other pleasant things.

She lifted her skirts as she crossed the street. Her new stockings and boots and gloves had worked wonders for her appearance. They'd given her a feeling of satisfaction, a sense of belonging to the well-dressed crowds.

She

was

very

hungry.

Another time she would have ignored the desire for food until reaching her

own

home. 
But the force that was guiding her would not permit her to act on such a thought. There was a restaurant at the corner. She had never entered its doors. She had sometimes looked through the windows. She had noted the white table cloths, shining glasses and waiters serving wealthy people.

When she entered, her appearance created no surprise or concern, as she had half feared it might. She seated herself at a small table. A waiter came at once to take her order. She ordered six oysters, a chop, something sweet, a glass of wine and a cup of coffee. While waiting to be served she removed her gloves very slowly and set them beside her. Then she picked up her magazine and looked through it.

It was all very agreeable. The table cloths were even more clean and white than they had seemed through the window. And the crystal drinking glasses shined even more brightly. There were ladies and gentlemen, who did not notice her, lunching at the small tables like her own. A pleasing piece of music could be heard, and a gentle wind was blowing through the window. She tasted a bite, and she read a word or two and she slowly drank the wine. She moved her toes around in the silk stockings. The price of it all made no difference. When she was finished, she counted the money out to the waiter and left an extra coin on his tray. He bowed to her as if she were a princess of royal blood.

There was still money in her purse, and her next gift to herself presented itself as a theater advertisement. When she entered the theater, the play had already begun. She sat between richly dressed women who were there to spend the day eating sweets and showing off their costly clothing. There were many others who were there only to watch the play.

It is safe to say there was no one there who had the same respect that Mrs. Sommers did for her surroundings. She gathered in everything — stage and players and people — in one wide sensation.

She laughed and cried at the play. 


\section{Yasmin M. Al-Sayed}

She even talked a little with the women.

One woman wiped her eyes with a small square of lace and passed Mrs. Sommers her box of candy. The play was over, the music stopped, the crowd flowed outside.

It was like a dream ended. Mrs. Sommers went to wait for the cable car. A man with sharp eyes sat opposite her. It was hard for him to fully understand what he saw in her expression. In truth, he saw nothing - unless he was a magician. Then he would sense her heartbreaking wish that the cable car would never stop anywhere, but go on and on with her forever.

\section{Credits}

You have heard the story "A Pair of Silk Stockings" by Kate Chopin. Your storyteller was Barbara Klein.

You can find the complete text and an MP3 file of this at: voanews.com/specialenglish/2009-09-04-voa1.cfm 